\title{
A cry for help: female distress calling during copulation is context dependent
}

Hanne Løvlie, Josefina Zidar and Christina Berneheim

\section{Linköping University Post Print}

\section{Tweet}

N.B.: When citing this work, cite the original article.

Original Publication:

Hanne Løvlie, Josefina Zidar and Christina Berneheim, A cry for help: female distress calling during copulation is context dependent, 2014, Animal Behaviour, (92), 151-157.

http://dx.doi.org/10.1016/j.anbehav.2014.04.002

Copyright: Elsevier Masson

http://www.elsevier-masson.fr/

Postprint available at: Linköping University Electronic Press

http://urn.kb.se/resolve?urn=urn:nbn:se:liu:diva-106499 
A cry for help: female distress calling during copulation is context dependent

Hanne Løvlie $^{\mathrm{ab}} *$, Josefina Zidar ${ }^{\mathrm{ab}}$, Christina Berneheim ${ }^{\mathrm{c}}$

${ }^{\mathrm{a} D e p a r t m e n t ~ o f ~ Z o o l o g y, ~ S t o c k h o l m ~ U n i v e r s i t y, ~ S t o c k h o l m, ~ S w e d e n ~}$

${ }^{\mathrm{b}}$ Department of Physics, Chemistry and Biology, IFM Biology, Linköping University, Linköping, Sweden

${ }^{\mathrm{c}}$ School of Biological Sciences, the University of Edinburgh, Edinburgh, U.K.

Received 21 December 2013

Initial acceptance 17 February 2014

Final acceptance 12 March 2014

MS. number: 13-01054R

*Correspondence: H. Løvlie, Department of Physics, Chemistry and Biology, IFM Biology, Linköping University, Campus Valla, SE-58183 Linköping, Sweden.

E-mail address: hanne.lovlie@liu.se (H. Løvlie).

Keywords: copulation call, domestic fowl, Gallus gallus domesticus, mate choice, sexual conflict

\section{ABSTRACT}

Owing to selection for increased mating propensity, males often expose females to sexual harassment. Consequently, females may evolve counterstrategies to retain control of mating. Females can do this directly by resisting copulations, or indirectly by manipulating other 
males to intervene and prevent the copulation. Uttering copulation calls may be one indirect method for females to trigger male intervention. Copulation calls are commonly observed in mammals, primarily in primates, and also in some birds. Female fowl, Gallus gallus, sometimes utter calls during copulation, particularly in forced copulations with low-ranking males. These loud calls, called distress calls, attract other males and can result in disruption of the copulation, and subsequent mating with the intervening male if he is high ranking. Consequently, uttering such calls can act both to abort a coerced copulation and to generate novel opportunities for females to copulate with higher-ranking males. Nevertheless, uttering loud calls can carry costs, such as attracting predators. Females are therefore predicted to utter copulation calls primarily when doing so offers benefits, which for female fowl requires the presence of another high-ranking male. We tested this prediction by altering the social environment of female domestic fowl, G. g. domesticus. We found that females uttered copulation calls more frequently during copulations in the presence of dominant 'observer' males than in their absence. Thus, we provide evidence of context-dependent utterance of female calls during copulations in a bird. This type of female vocalization is rarely investigated in nonprimate vertebrates, but increased research in this field offers potential to improve understanding of female mate choice strategies and the dynamics of sexual selection. 


\section{INTRODUCTION}

Males and females typically adopt different reproductive strategies to optimize their reproductive success (Bateman, 1948; Trivers, 1972; Parker, 1979; Andersson, 1994), which can result in sexual conflict over mating (Parker, 1979, 2006; Arnqvist \& Rowe, 2005). Owing to sex-specific investment in offspring, males are typically selected for high mating rates (Bateman, 1948; Parker, 1979; Andersson, 1994), and females are selected to prefer high-quality mates (Andersson, 1994; Andersson \& Simmons, 2006). This sexual conflict may select for a range of male and female mating strategies, including selection on males to constrain female precopulatory choice through coerced copulations (Parker, 1979; Parker, 2006). Females may counteract male sexual harassment in an attempt to retain some control over mate choice (Andersson, 1994; Parker, 2006). To do this, females can resist copulation attempts by nonpreferred males directly, or when this is not possible, too costly or unsuccessful, females may attempt to manipulate male behaviour to their advantage, or bias paternity after copulation (Andersson, 1994; Eberhard, 1996). Female strategies aimed at manipulating male behaviour have received relatively limited attention, compared with direct female choice or male-male competition. This is particularly true for female vocalization associated with copulation, which is a suggested mechanism by which females can manipulate male behaviour (e.g. Semple, 1998; Pradhan et al., 2006).

A copulation call is a loud call uttered in association with copulation (Trivers, 1972; Birkhead \& Møller, 1992; Semple, 1998; Pradhan et al., 2006). Although copulation calls can be very distinctive, their adaptive function is only partially understood. Copulation calls by females appear to influence male sexual behaviour by attracting males to the copulation, thereby increasing male-male competition both prior to (e.g. elephant seal, 
Mirounga angustirostris, Cox \& Le Boeuf, 1977) and after copulation (e.g. baboons, Papio cynocephalus ursinus, O’Connell \& Cowlishaw, 1994). For example, copulation calls uttered by female Barbary macaques, Macaca sylvanus, induce competition among males, resulting in copulation between the dominant male and the calling female. The female can thus attract a higher-quality mating partner by uttering copulation calls (Semple, 1998). In Alaskan moose, Alces alces gigas, females utter 'protest moans' when courted by small or medium-sized males, leading to increased male-male aggression and reduced sexual harassment by smaller males (Bowyer et al., 2011). Uttering copulation calls in the presence of high-quality males may therefore be an important mechanism for female mate choice, particularly when females have limited precopulatory mate choice and are exposed to forced copulations by low-quality males.

In birds, the adaptive function of female vocalization is generally poorly understood (Langmore, 1998). Nevertheless, female vocalization associated with copulation can be a strategy to attract males (Montgomerie \& Thornhill, 1989; Birkhead \& Møller, 1992; Ekstrom et al., 2007).

Both female domestic fowl and their ancestor the red junglefowl, Gallus gallus, sometimes utter loud calls during copulation, named distress calls (Collias, 1987; Pizzari, 2001). These calls are associated with forced copulations, and are more frequent when the male is low ranking (Pizzari, 2001). Male fowl are attracted to the calling female and increased male-male competition is triggered, which often results in abortion of the initial copulation attempt, at least when the attracted male is of higher rank than the male already attempting to copulate with the female (Pizzari, 2001). In addition, or instead, copulation 
between the female and the interrupting male can take place (Pizzari, 2001). The production of these loud calls can therefore carry both potential costs (i.e. attracting an unwanted audience such as predators: Högstedt, 1983; Klump \& Shalter, 1984; Koenig et al., 1991; Krams, 2001) and benefits (i.e. if unwanted copulation attempts are aborted, e.g. Semple, 1998; Pizzari, 2001; Bowyer et al., 2011). Females are thus predicted to produce these calls in forced copulations, and particularly when another male is near. Studies on context-dependent utterance of copulation calls are scarce, despite the potential such studies have for improving our understanding of female mate choice strategies, female manipulation of male behaviour and the interaction between intra- and intersexual selection. In primates, for which female copulation calls are relatively well studied, context dependence in female propensity to utter these calls has been shown. For example, female bonobos, Pan paniscus, that engage in copulations with partners of both sexes are more likely to utter copulation calls in copulations with males than with females, and are more likely to do so in the presence of a higher-ranking individual (Clay et al., 2011; Clay \& Zuberbuhler, 2012). In contrast, in the fowl it remains unclear whether variation in the frequency of female call production is explained by the presence of other, particularly high-ranking, males, or another factor, for example male behaviour explained by rank.

In this study, we investigated whether females showed context-dependent variation in distress calls uttered during copulations by including an additional, dominant male during a proportion of copulations. Altering the absence or presence of a dominant male that could potentially abort the copulation attempt modifies the potential benefit to a female of uttering distress calls. By investigating variation in female copulation call propensity, we 
aimed to elucidate female mating strategies in general and the function of female vocalization in indirect mate choice more specifically.

\section{METHODS}

\section{Study species}

In the domestic fowl and its wild ancestor the red junglefowl (Fumihito et al., 1994), individuals form groups characterized by social hierarchies and intense sexual selection (Collias \& Collias, 1996; Pizzari et al., 2002). Male fowl have a large secondary sexual ornament, a red fleshy comb, for which size correlates positively with status (Ligon et al., 1990; Parker \& Ligon, 2002; Cornwallis \& Birkhead, 2008) and signals quality (Hamilton \& Zuk, 1982; Zuk, Thornhill, Ligon et al., 1990). Males of high rank and/or those with a large comb are preferred by female fowl as mating partners (Zuk, Thornhill, Johnson et al., 1990; Pizzari \& Birkhead, 2000; Pizzari, 2001; Pizzari et al., 2002). The comb and status are the only male traits that are consistently demonstrated to affect female mate choice in the fowl (Zuk, Thornhill, Ligon, et al., 1990; Pizzari \& Birkhead, 2000; Pizzari, 2001; Pizzari et al., 2002). Female precopulatory mate choice in the species is limited and males initiate most copulations (over 90\%), often through sexual coercion (Pizzari, 2001; Løvlie \& Pizzari, 2007). To avoid copulations, female fowl can to some extent affect the outcome of a mating attempt by showing direct resistance to males (Pizzari, 2001; Løvlie \& Pizzari, 2007). Because males interfere with each other's mating attempts, and dominant males in particular will interfere with copulation attempts made by subdominant males (Pizzari, 2001), females can also reduce the success of copulations with lower-ranking males by attracting higherranking males by uttering distress calls (Pizzari, 2001). 


\section{Study population}

We used birds from a population of an old Swedish game breed of fowl ('Gammal svensk dvärghöna', Harrison, 1987) at Tovetorp Research Station (Stockholm University, Sweden; population sizes: 2010: $N_{\text {females }}=64, N_{\text {males }}=52 ; 2011: N_{\text {females }}=65, N_{\text {males }}=60$ ). The study was carried out during May-June 2010 and July-August 2011, during the birds' breeding season. Birds were kept under seminatural conditions, with mixed-sex, mixed-age (1-10 years) subgroups kept in outdoor aviaries (ca. 5 x $10 \mathrm{~m}$ and 3.5 high) with ad libitum access to water, commercial poultry feed, perches, dust baths and shelters. The population has not been bred for commercial purposes, and as a consequence the birds are very similar both in morphology and in behaviour to the red junglefowl. Birds are fitted with leg bands with individual identity numbers facilitating recognition.

\section{Experimental Set-up}

To investigate variation in female call frequency during copulations and the influence of the presence or absence of an additional, dominant male, 30 randomly chosen sexually mature females were individually exposed to two treatments. Females were housed together with (1) a single male with no visual access to other males ("Absence of an additional, dominant male'), or (2) a subdominant male, with a dominant male housed in a separate enclosure further away, but within visual distance (2-5 m, i.e. 'Presence of an additional, dominant male'). Both treatments lasted for 2 days. Each female was exposed to the two treatments, but in random order. 
Both male and female fowl are sexually promiscuous (Pizzari et al., 2002) and previous sexual history reduces female propensity to remate. Female remating propensity is clearly reduced when comparing first versus successive days of access to males and matings, after females have been sexually rested and housed without males for 14 days, which is the mean time for which females store sperm (Løvlie et al., 2005; Løvlie \& Pizzari, 2007 and references therein). Therefore, females were housed in groups with multiple, sexually active males (more than five males not taking part in the experiment) up until 2 days prior to the experiment. This was done to ensure that females had recently mated with multiple males, and thus would not mate indiscriminately with low-quality males (e.g. because of a lack of stored sperm). Males were sexually rested for a minimum of 2 days prior to the experiments to encourage mating propensity (Parker et al., 1942; Løvlie \& Pizzari, 2007). Combs of experimental males ( $N=53$, see below) were measured with digital callipers to the nearest 0.1 $\mathrm{mm}$ up to 1 week before the experiments. Comb length was used both as a measure of male social rank (Zuk, Thornhill, Ligon et al., 1990; Parker \& Ligon, 2002; Cornwallis \& Birkhead, 2008) and also because female fowl prefer males with larger combs (Zuk, Thornhill, Ligon et al., 1990). Males were allocated to treatments so that 'Single' males (males taking part in the treatment 'Absence of an additional, dominant male', see below) did not have larger combs than paired males. This was done to reduce the potential that 'Single' males were perceived as dominant because of the lack of males available to the female for direct comparison, which could potentially bias female propensity to utter distress calls in this treatment in a way not explained by the presence or absence of an 'observer' male. In the pair treatment ('Presence of an additional, dominant male', see below), male status was confirmed by direct observations of social interactions when the male pair was set up. We regarded a male as subdominant when he avoided the other male (the dominant male) at least three times. 
Owing to limitations of available males in the population, some males $(N=28)$ were used more than once in the experiments. Males used multiple times were never used twice with the same female or in the same male combinations, and were most typically used in different years. Behavioural observations were conducted at a distance of approximately $>6 \mathrm{~m}$ from the aviaries housing the birds, and during the peaks in copulation activity in this population, which is around 0400-0800 and 1600-2100 hours local time (Pizzari \& Birkhead, 2001; Løvlie \& Pizzari, 2007). Morning observations typically lasted 180 min and began when the female left the roost; evening observations started at 1600 hours and continued until the female had gone to roost, and were thus always longer than $180 \mathrm{~min}$.

\section{Absence of an Additional, Dominant Male}

On the morning of observation day 1 , around $0730-0800$ hours, a female was placed in an outdoor aviary (ca. $3 \times 4 \mathrm{~m}$ and $3.5 \mathrm{~m}$ high). A single male was placed in an adjacent pen enabling the female to observe the male during the day. At 1600 hours the same day, the male was allowed into the female's cage initiating the observation period (see below).

\section{Presence of an Additional, Dominant Male}

Similarly to when exposed to a single male, each female was placed alone in the experimental pen on the morning of observation day 1 , starting at $0730-0800$ hours. However, in this treatment, a pair of males was placed together in the pen adjacent to the female. In full view of the female, social rank was established between the males (by aggressive behaviours until one of them showed clear and repeatable submission, Guhl, 1962; Queiroz \& Cromberg, 2006). The female was allowed to observe the males throughout the day. At the start of the 
observation at 1600 hours, the subdominant male was let into the female's pen while the dominant male was placed in a pen somewhat further away from the female (ca. $3 \mathrm{~m}$ ), although still with full visual and acoustic access. The dominant male was placed further away to prevent him to interfere directly with the subdominant male's copulations.

\section{Behavioural Observations}

All observed copulation attempts were recorded. Copulation attempts were recorded as initiated by a female when females actively solicited copulations by crouching in front of the male (sensu Løvlie et al., 2005; Løvlie \& Pizzari, 2007). All other copulation attempts were recorded as initiated by a male. Female willingness to mate was also scored by recording whether any resistance was observed during a copulation attempt (sensu Løvlie et al., 2005; Løvlie \& Pizzari, 2007). Only copulation attempts resulting in mounting were recorded as 'copulations'. All copulations were recorded as behaviourally 'successful' if the male was observed lowering his tail over the female's cloaca, and insemination could be assumed to have occurred (sensu Løvlie \& Pizzari, 2007). Copulations where a male mounted a female, but did not lower his tail over the cloaca were recorded as 'unsuccessful'. Whether a female uttered a distress call or not was recorded in all observed copulation attempts.

To investigate how the absence and presence of a male in the neighbouring pen influenced the female's behaviour, the location of the female within her pen was recorded every 15 min (recorded as 'near' or 'far'; 'near' if the female was in the half of her pen close to the neighbouring pen, 'far' when the female was located in the other half of her pen). 


\section{Data Analyses}

Twenty-nine females were exposed to copulation attempts both in the absence and in the presence of an additional, dominant male. For these females, the following behaviours were calculated per female, and treatment, and analysed for each of the two treatments to which they were exposed: number of female-initiated copulation attempts and copulations (the total number of female-initiated copulation attempts and copulations), number of male-initiated copulation attempts and copulations (the total number of copulation attempts and copulations initiated by a male), total number of copulation attempts (the total number of copulation attempts to which a focal female was exposed), number of copulations (the total number of copulation attempts that resulted in mounting), number of successful copulations (the total number of copulation attempts that were behaviourally successful), number of copulation attempts where female resistance was observed (the total number of copulation attempts and copulations a female resisted), number of copulation attempts where female distress calls were observed (the total number of distress calls uttered by females during copulation attempts and copulations), probability of female resistance (the total number of copulation attempts and copulations with female resistance divided by the number of copulation attempts and copulations), probability of female distress call (the total number of female-uttered distress calls in copulation attempts and copulations divided by the number of copulation attempts and copulations). We also analysed variation in male comb size (male comb length). Owing to the lack of normally distributed data, data were compared between the two treatments with Wilcoxon matched-pair tests or chi-square tests, while relationships between continuous variables were investigated with Spearman rank correlations. Analyses were performed in Statistica version 10 (Statistica, Statsoft, Tulsa, OK, U.S.A.). 
To explore further whether the observed differences in female distress call frequencies were explained by differences in whether an additional, dominant male was present or absent, we carried out two analyses using generalized linear mixed models (GLMM). First, variation in 'total number of female-uttered distress calls in copulation attempts' was analysed through a GLMM with 'treatment' (i.e. absence or presence of an additional, dominant male) added as a fixed effect, and 'the number of copulation attempts and copulations to which the female was exposed' entered as a covariate. 'Female identity' and 'male identity' were entered as random effects. Second, a model constructed in the same way as above was used to investigate variation in 'total number of copulation attempts and copulations to which a female showed resistance'. These two GLMMs were fitted with Poisson distributions, and corrected for overdispersion. Analyses were conducted in SAS 9.3 (SAS Institute, Cary, NC, U.S.A.).

\section{Ethical Note}

The experiment was conducted according to ethical requirements in Sweden (Linköping Ethical committee, ethical permit number 60-10).

Individuals from this population are habituated to humans owing to regular use in behavioural studies (e.g. Pizzari et al., 2003; Løvlie et al., 2005; Zidar \& Løvlie 2012; Favati et al., 2014), thus allowing us to catch the birds by hand, and observe natural behaviours at a relatively short distance with limited or no signs of stress. The experimental housing used in the current study was very similar to that of the stock housing, with ad libitum access to dust baths, perches, nestboxes, water and feed. The health and wellbeing of 
birds were checked several times a day, by the researchers and a game keeper responsible for the daily care of the birds. After participation in a study, birds were released back to the main aviaries, which is where they remain in mixed-age populations until they die. Injured or sick animals are put down according to ethical permits by a trained game keeper or the veterinarian, and the large majority of the birds die a natural death from old age.

In the wild, groups and social hierarchies of feral domestic fowl and red junglefowl are relatively stable, although some alteration in positions between individuals do occur (McBride et al., 1969; Collias \& Collias 1996). Similarly to many other social animals with dominance hierarchies, the establishment of social rank typically escalates only when individuals cannot assess rank based on phenotypic traits used in intrasexual selection. The birds used in this study were all from a mixed-sex, mixed-age population, and thus individuals were socialized and exposed to similar changes and social interactions as natural flocks. As a result, social rank was typically established by means that did not lead to injuries. Phenotypic traits (mainly comb size) affect the outcome of social interactions (e.g. Ligon et al., 1990; Parker \& Ligon, 2002; Cornwallis \& Birkhead, 2008). Social status of males is typically determined in the first couple of minutes after birds are released together, primarily through ritualized threats (raised hackle, dropped wings, see Kruijt, 1964; Favati, Leimar, \& Løvlie, n.d.) leading to one male avoiding the other, a short chase by the (dominant) male, or a short fight between the two. The aviaries used to house birds contain perches and structures that subdominant males can use to avoid the dominant male if needed. In this study we used males that were experimentally mismatched for comb size, which is expected to reduce escalation of aggression since males with larger combs typically become dominant. No birds were injured during the study. The experimenter observing birds during initial interactions was instructed 
to disrupt any fights that escalated or lasted for longer than $1 \mathrm{~min}$, but this did not occur. Males were housed together for approximately $8 \mathrm{~h}$. Males and females were housed together for 2 days (see above).

\section{RESULTS}

\section{Occurrence of Distress Calls in Copulations}

We observed 486 copulation attempts. Females were recorded to utter distress calls in 146 of these, both during copulation attempts and during copulations. Significantly more distress calls were uttered during copulations than during copulation attempts (66 distress calls recorded in 275 copulation attempts, $24.0 \%$; 80 distress calls recorded in 211 copulations, $\left.37.9 \% ; \chi_{1}^{2}=11.0, P=0.001\right)$. All recorded distress calls were uttered during male-initiated copulation attempts; thus females were never observed to utter distress calls when initiating copulations. Females were significantly more likely to utter distress calls if they also showed resistance towards the male during the same copulation attempt (in only 10 of 118 copulation attempts where females showed no resistance did females utter distress calls, $8.5 \%$, versus 136 of 379 copulations where females showed resistance and also uttered distress calls, $\left.35.9 \% ; \chi_{1}^{2}=23.4, P=0.0001\right)$.

\section{Absence and Presence of an Additional, Dominant Male}

Males initiated more copulation attempts in the treatment in which an additional, dominant male was present. Consequently, this treatment also had more successful copulations, even though there was no difference in the number of copulations that females initiated between 
the two treatments (Table 1). Females resisted more copulation attempts and uttered more distress calls in the presence of the additional dominant male (Tables 1, 2). Thus, we controlled for this difference by calculating the proportion of female resistance and distress calls between the two treatments; the proportion of female resistance to copulation attempts did not differ between the two treatments, whereas the proportion of distress calls in copulation attempts was still higher in the presence of a dominant male than when the female was alone with a male (Tables 1, 2, Fig. 1).

\section{Female Attraction to the Neighbouring Pen}

Females spent significantly more time near the neighbouring pen when it housed an additional, dominant male than when it was empty (probability of being close to the neighbouring pen, in the absence of another male: $0.50 \pm 0.04$; in the presence of another male: $0.65 \pm 0.03 ; Z=3.69, P=0.0002$; Fig. 2). Females that spent more time close to the additional male's pen also uttered more distress calls in male-initiated copulation attempts and copulations $\left(r_{\mathrm{S}}=0.37, N=29, P=0.051\right)$. Time spent close to the pen housing the additional, dominant male was not dependent on his comb size $\left(r_{\mathrm{S}}=0.23, N=29, P=0.24\right)$. Similarly, neither the comb size of the subdominant male with which the female was housed (subdominant male: $r_{\mathrm{S}}=0.07, N=29, P=0.71$ ) nor the difference between the comb size of the subdominant male and the dominant male $\left(r_{\mathrm{S}}=0.11, N=29, P=0.58\right)$ explained whether females spent more time close to the neighbouring pen.

Male Comb Size 
Males confirmed to be dominant in the pair treatment had larger combs than males that were confirmed to be subdominant (comb sizes: dominant males: mean \pm SE: $81.2 \pm 1.1 \mathrm{~mm}$; subdominant males: mean \pm SE: $66.6 \pm 1.2 \mathrm{~mm} ; Z=4.70, P \leq 0.0001)$. Single males had smaller combs than males in the pair treatment (mean \pm SE: $56.4 \pm 1.5 \mathrm{~mm}$; versus dominant male: $Z=4.68, P \leq 0.0001$; versus subdominant male: $Z=3.95, P=0.0008$ ).

\section{DISCUSSION}

We confirmed that female fowl utter distress calls in coerced copulations, primarily when also showing behavioural resistance to copulation attempts. Females were more likely to utter distress calls in the presence of another, dominant male. Thus, our results demonstrate that female fowl utter distress calls during copulations in a context-dependent manner.

Male mating propensity was affected by the presence of another male, and (subdominant) males initiated more copulations in their presence. Male fowl respond sophisticatedly and flexibly to variation in perceived level of sperm competition (Pizzari et al., 2003); thus the increased mating propensity may be caused by the perceived alteration of sperm competition the presence of another male imposes. Increased exposure to copulations and/or male constraint of female precopulatory mate choice generally selects for female strategies to gain control of mating (Parker, 1979; Andersson, 1994; Eberhard, 1996; Arnqvist \& Rowe, 2005). Females may attempt to do this by directly resisting copulation attempts or through alternative mate choice strategies. The increased exposure to sexual harassment female fowl faced in the presence of an additional male triggered female resistance to copulation attempts. However, when we controlled for the variation observed between 
treatments in number of copulation attempts to which females were exposed, the probability of females showing resistance in copulation attempts was similar between the two social contexts. Females chose to be closer to the pen in which the dominant male was housed than if the pen was vacant and no other males were present. Female fowl may do this in an attempt to associate with the additional (higher-ranking) male and avoid forced copulations by lowerquality, subdominant males (as observed for female Sumatran orang-utans, Pongo pygmaeus abelii, Fox, 2002). In addition, females uttered relatively more distress calls in the presence of an additional, dominant male than in his absence. Taken together this suggests that the observed higher frequency of distress calls uttered during copulation attempts was explained not by increased sexual harassment but instead by the actual absence or presence of another, dominant male. Our results demonstrate that female fowl utter distress calls dependent on social context and uttering these calls can therefore function as a means for females to manipulate male behaviour.

The variation in uttering distress calls by female fowl that we observed indicates that there may be both costs and benefits associated with uttering these calls. Benefits from uttering distress calls can be both direct and indirect: direct, if an unwanted copulation is interrupted and indirect, if making the distress calls contributes to biased copulation success in favour of a dominant male (Pizzari, 2001). Producing loud noises to attract the attention of dominant males will, however, potentially also attract undesired males or predators within receiving range of the call (Högstedt, 1983; Klump \& Shalter, 1984; Koenig et al., 1991; Krams, 2001). Such undesirable attention may affect females' propensity to utter distress calls under certain social or environmental conditions. The exact quality or status of the harassing male may be particularly relevant for predicting female propensity to utter distress calls. For 
example, the rate of protest moans from female Alaskan moose decreased with increased size of the male (Bowyer et al., 2011) and the probability of a male elephant seal being interrupted after a distress call made by the female was directly associated with his rank: when females uttered distress calls, the chance of the copulation being interrupted increased with the lower rank of the harasser (Cox \& Le Boeuf, 1977). A similar relationship between number of interrupted copulations and the rank of the harasser has also been observed in domestic fowl, in which more high-ranking males typically interrupt lower-ranking males' copulations (Pizzari, 2001). In our study, since females were not acoustically isolated from other males in the population, the observed increase in distress calls in the presence of another male clearly shows that females rely on proximity or visual cues when deciding whether to utter distress calls in forced copulations. In the current study, the females' response could in principle be caused by her realization that an additional male was near, independent of his social status. The exact role that the rank of the additional male plays in female responses could be investigated further by observing female responses to nearby males of varying rank. Nevertheless, males housed singly with females had smaller combs than other males used in the study, a predictor of low social status in male fowl (e.g. Ligon et al., 1990; Parker \& Ligon, 2002; Cornwallis \& Birkhead, 2008). Singly housed males were thus probably perceived as subdominant males (and not dominant males) because of their smaller comb, even if other males enabling a direct comparison were absent. We therefore conclude that the increased utterance of distress calls by females in the presence of an additional male was a consequence of his higher dominance (and larger comb), and not only because of the presence of an additional male. The additional males in our study were both dominant and had larger combs; thus we were not able to disentangle which of these cues was used by females. However, the probability of females uttering distress calls in copulations appeared to be independent of variation in male comb size (or differences between comb sizes in males, in 
the paired treatment) suggesting that male status is the more important cue for female fowl. To further our understanding of the role that social rank and morphology have on female utterance of distress calls, additional studies are encouraged.

Many studies are devoted to the investigation of female choice or male-male competition, whereas studies of indirect mate choice strategies and inter- and intrasexual selection in combination are scarce and therefore these are less well understood. Indirect mate choice occurs when females choose mates indiscriminately of their direct attributes, and when female behaviour restricts the set of potential mates. By taking advantage of male-male competition rather than applying direct mate choice and the potential associated cost of resistance, indirect mate choice may be an alternative strategy for females in obtaining highquality mating partners (Kokko et al., 1999). Several female behaviours manipulating male behaviour can mediate indirect female choice. For example, female hermit crabs, Pagurus filholi, excrete pheromones that trigger male-male competition resulting in mate guarding by the largest male (Okamura \& Goshima, 2010). Female Alaskan moose utter 'protest moans' when courted by small males, which trigger male-male competition and reduce male sexual harassment of females (Bowyer et al., 2011). Female fowl probably gain similar benefits by uttering distress calls, in other words increasing male-male competition and a chance of copulating with more dominant males. Copulation calls thus seem to function both to attract males to disrupt an unwanted copulation and to attract higher-quality males, thus providing higher-quality copulation opportunities. However, the specific adaptive function of vocalization during copulation is still debated and likely to be species-specific (Pradhan et al., 2006). For example, in the Emei music frog, Babina daunchina, females produce low- 
intensity clicking calls that stimulate males' movements in copulations, suggested to stimulate male sexual activity (Cui et al., 2010).

Direct and indirect female mate choice can have the potential to select for different male traits (e.g. direct mate choice for male ornament; indirect mate choice for traits favoured in male-male competition). However, these selective pressures are likely to coincide in the fowl when high-ranking males are preferred through both direct and indirect precopulatory female mate choice (Pizzari, 2001; Pizzari et al., 2002; Dean et al., 2010) together with certain postcopulatory female mate choice mechanisms (e.g. Pizzari and Birkhead, 2000; but see Pizzari et al., 2004; Løvlie et al., 2013). As a result, female mating preferences in the fowl are likely to exaggerate the intersexual conflict between subdominant males and females, with the potential to trigger selection for further counteradaptations in both sexes.

\section{ACKNOWLEDGMENTS}

We are grateful to Nils Andbjer for taking care of the birds, Kristin Nilsson for help during the experiments, and Rebecca F. Dean, Alexander Hayward, and the referees for useful comments on the manuscript.

\section{REFERENCES}

Arnqvist, G., \& Rowe, L. (2005). Sexual conflict. Princeton, NJ: Princeton University Press. Andersson, M. (1994). Sexual selection. Princeton, NJ: Princeton University Press. 
Andersson, M., \& Simmons, L. W. (2006). Sexual selection and mate choice. Trends in Ecology \& Evolution, 21, 296-302.

Bateman, A. J. (1948). Intra-sexual selection in Drosophila. Heredity, 2, 349-368.

Birkhead, T. R., \& Møller, A. P. (1992). Sperm competition in birds: Evolutionary causes and consequences. Cambridge, UK: Cambridge University Press.

Bowyer, R. T., Rachlow, J. L., Stewart, K. M., \& Van Ballenberghe, V. (2011). Vocalizations by Alaskan moose: female incitation of male aggression. Behavioral Ecology and Sociobiology, 65, 2251-2260.

Clay, Z., Pika, S., Gruber, T., \& Zuberbuhler, K. (2011). Female bonobos use copulation calls as social signals. Biology Letters, 7, 513-516.

Clay, Z., \& Zuberbuhler, K. (2012). Communication during sex among female bonobos: effects of dominance, solicitation and audience. Scientific Reports, 291, 1-8.

Collias, N. E., \& Collias, E. C. (1996). Social organization of a red junglefowl, Gallus gallus, population related to evolution theory. Animal Behaviour, 51, 1337-1354.

Collias, N. E. (1987). The vocal repertoire of the red junglefowl: a spectrographic classification and the code of communication. Condor, 89, 510-524.

Cornwallis, C. K., \& Birkhead, T. R. (2008). Plasticity in reproductive phenotypes reveals status-specific correlations between behavioral, morphological, and physiological sexual traits. Evolution, 62, 1149-1161.

Cox, C. J., \& LeBoeuf, B. J. (1977). Female incitation of male competition: a mechanism of mate selection. American Naturalist, 111, 317-335.

Cui, J. G., Wang, Y., Brauth, S. E., \& Tang, Y-Z. (2010). A novel female call incites malefemale interaction and male-male competition in the music frog, Babina daunchina. Animal Behaviour, 80, 181-187. 
Dean, R. F., Cornwallis, C. K., Løvlie, H., Worley, K., Richardson, D. S., \& Pizzari, T. (2010). Male reproductive senescence causes potential for sexual conflict over mating. Current Biology, 20, 1192-1196.

Eberhard, W. G. (1996). Female control: sexual selection by cryptic female choice. Princeton, NJ: Princeton University Press.

Ekstrom, J. M. M., Burke, T., Randrianaina, L. \& Birkhead, T. R. (2007). Unusual sex roles in a highly promiscuous parrot: the greater vasa parrot Caracopsis vasa. Ibis, 149, 313320.

Favati, A., Leimar, O., \& Løvlie, H. (n.d.). [Exploration, vigilance and aggression independently predict social dominance in male domestic fowl] Manuscript submitted for publication.

Favati, A., Leimar, O., Radesäter, T. \& Løvlie, H. (2014). Social status and personality: stability in social state can promote consistency of behavioural responses. Proceedings of the Royal Society B, 281, 20132531.

Fox, E. (2002). Female tactics to reduce sexual harassment. Behavioral Ecology and Sociobiology, 52, 93-101.

Fumihito, A., Miyake, T., Sumi, S., Takada, M., Ohno, S., \& Kondo, N. (1994). One subspecies of the red jungle fowl (Gallus gallus gallus) suffices as the matriarch ancestor of all domestic breeds. Proceedings of the National Academy of Sciences USA, 91, 1250512509.

Guhl, A. M. (1962). The behaviour of chickens. In Hafez ESE. (Ed.). The Behaviour of Domestic Animals, pp, 491-530. London, UK: Bailliere, Tindall \& Cox.

Hamilton, W. D., \& Zuk, M. (1982). Heritable true fitness and bright birds: a role for parasites? Science, 218, 384-387. 
Harrison, B. (1987). Den svenska dvärghönan. II. Svenska rasfjäderfäförbundets tidsskrift, 1, $12-14$.

Högstedt, G. (1983). Adaptation unto death -function of fear screams. American Naturalist, $121,562-570$.

Krams, I. (2001). Communication in crested tits and the risk of predation. Animal Behaviour, $61,1065-1068$.

Kruijt, J. P. (1964) Ontogeny of social behaviour in Burmese red junglefowl (Gallus gallus Spadiceus) Behaviour (Supplement), 12, 1-201.

Klump, G. M., \& Shalter, M. D. (1984). Acoustic behaviour of birds and mammals in the predator context. Zeitschrift für Tierpsychologie, 66, 189-226.

Koenig, W. D., Stanback, M. T., Hooge, P. N., Mumme, R. L. (1991). Distress calls in the acorn woodpecker. Condor, 93, 637-643.

Kokko, H., Rintamaki, P. T., Alatalo, R. V., Höglund, J., Karvonen, E., \& Lundberg, A. (1999). Female choice selects for lifetime lekking performance in black grouse males. Proceedingsof the Royal Society of London B, 266, 2109-2115.

Langmore, N. E. (1998). Functions of duets and solo songs of female birds. Trends in Ecology \& Evolution, 4, 136-140.

Ligon, J. D., Thornhill, R., Zuk, M., \& Johnson, K. (1990). Male male competition, ornamentation and the role of testosterone in sexual selection in red jungle fowl. Animal Behaviour, 40, 367-373.

Løvlie, H., \& Pizzari, T. (2007). Sex in the morning or in the evening? Females adjust daily patterns to the intensity of sexual harassment. American Naturalist, 170, 1-13.

Løvlie, H., Cornwallis, C. K., \& Pizzari, T. (2005). Male mounting alone reduces female promiscuity in the fowl. Current Biology, 15, 1222-1227. 
Løvlie, H., Gillingham, M. A. F., Worley, K., Pizzari, T., \& Richardson, D. S. (2013). Cryptic female choice favours sperm from major histocompatibility complex-dissimilar males. Proceedings of the Royal Society of London B, 280, 20131296.

McBride, G., Parer, I. P., \& Foenander, F. (1969). The social organisation and behaviour of the feral domestic fowl. Animal Behaviour Monograph, 2, 125-181.

Montgomerie, R., \& Thornhill, R. (1989). Fertility advertisement in birds: a means of inciting male-male competition? Ethology, 81, 209-220.

Parker, G. A. (1979). Sexual selection and sexual conflict. In Blum, M. S. \& Blum, N. A. (Eds.). Sexual selection and reproductive competition in insects, pp, 123-166. New York: Academic Press.

Parker, G. A. (2006). Sexual conflict over mating and fertilization: an overview. Philosophical Transactions of the Royal Society of London B, 361, 235-259.

Parker, J. E., McKenzie, F. F., \& Kempster, H. L. (1942). Fertility in the male domestic fowl. Missouri Agricultural Experiment Station Research Bulltin, 347, 3-50.

Parker, T. H., \& Ligon, J. D. (2002). Dominant male red junglefowl (Gallus gallus) test the dominance status of other males. Behavioral Ecology and Sociobiology, 53, 20-24.

Pradhan, G. R., Engelhardt, A., van Schaik, C. P., \& Maestripieri, D. (2006). The evolution of female copulation calls in primates: a review and a new model. Behavioral Ecology and Sociobiology, 59, 333-343.

Pizzari, T. (2001). Indirect partner choice through manipulation of male behaviour by female fowl, Gallus gallus domesticus. Proceedings of the Royal Society of London B, 268, 181186.

Pizzari, T., \& Birkhead, T. R. (2000). Female feral fowl eject sperm of subdominant males. Nature, 405, 787-789. 
Pizzari, T., \& Birkhead, T. R. (2001). For whom does the hen cackle? The function of postoviposition cackling. Animal Behaviour, 61, 601-607.

Pizzari, T., Froman, D. P., \& Birkhead, T. R. (2002). Pre- and post-insemination episodes of sexual selection in the fowl, Gallus g. domesticus. Heredity, 88, 112-116.

Pizzari, T., Cornwallis, C. K., Løvlie, H., Jakobsson, S., \& Birkhead, T. R. (2003). Sophisticated sperm allocation in male fowl. Nature, 426, 70-74.

Pizzari, T., Løvlie, H., \& Cornwallis, C. K. (2004). Sex-specific, counter-acting responses to inbreeding in a bird. Proceedings of the Royal Society of London B, 271, 2115-2121.

Okamura, S., \& Goshima, S. (2010). Indirect female choice mediated by sex pheromones in the hermit crab Oagurus filholi. Journal of Ethology, 28, 323-329.

O'Connell, S. M., \& Cowlishaw, G. (1994). Infanticide avoidance, sperm competition and mate choice: the function of copulation calls in female baboons. Animal Behaviour, 48, 687-694.

Saether, S. A. (2002). Female calls in lek-mating birds: indirect mate choice, female competition for males, or direct mate choice? Behavioral Ecology, 13, 344-352.

Semple, S. (1998). The function of Barbary macaque copulation calls. Proceedings of the Royal Society of London B, 265, 287-291.

Trivers, R. L. (1972). Parental investment and sexual selection. In Campbell B (Ed.) Sexual selection and the descent of man, 1871-1971, pp, 136-179. Chicago, IL: Aldine-Atherton.

Wiley, R. H., \& Poston, J. (1996). Indirect mate choice, competition for mates, and coevolution of the sexes. Evolution, 50, 1371-1381.

Queiroz, S. A., \& Cromberg, V. U. (2006). Aggressive behavior in the genus Gallus sp. Brazilian Journal of Poultry Science, 8, 1-14.

Zidar, J., \& Løvlie, H. (2012). Scent of the enemy: behavioural responses to predator faecal odour in the fowl. Animal Behaviour, 84, 547-554. 
Zuk, M., Thornhill, R., Ligon, J. D., Johnson, K., Austad, S., Ligon, S. H., Thornhill, N. W, \& Costin, C. (1990). The role of male ornaments and courtship behaviour in female mate choice of red jungle fowl. American Naturalist, 136, 459-473.

Zuk, M., Thornhill, R., Johnson, K., \& Ligon, J. D. (1990). Parasites and mate choice in red jungle fowl. American Zoologist, 30, 235-244. 


\section{Figure legends}

Figure 1. Distress calls uttered by female fowl $(N=29)$ during copulation attempts initiated by males (probability of distress call uttered in male-initiated copulation attempts and copulations) in the absence of an additional, dominant male ('Absence', empty column) versus when an additional, dominant male was present in the neighbouring pen ('Presence', filled column). Vertical lines represents SEs.

Figure 2. Attraction by female fowl $(N=29)$ to a neighbouring pen (proportion of time spent near the neighbouring pen), when the pen was empty ('Absence', empty column) versus when an additional, dominant male was inside ('Presence', filled column). Vertical lines represents SEs.

\section{Figure 1}

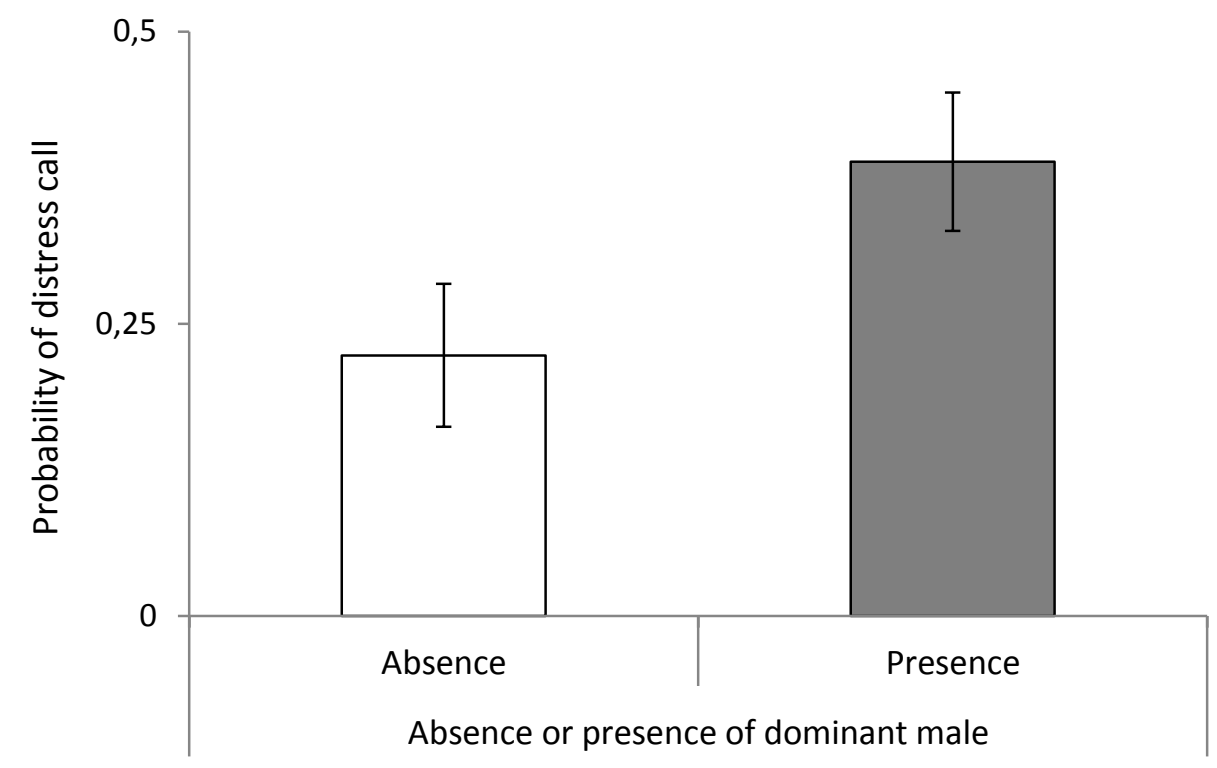


Figure 2




2 Tables

3 Table 1. Male and female fowl mating behaviour, in the absence and presence of an additional, dominant male

\begin{tabular}{lcccc}
\hline Behaviour & Absence & Presence & $Z$ & $P$ \\
\hline Number of female-initiated copulation attempts and copulations & $0.52 \pm 0.30$ & $0.17 \pm 0.09$ & 0.93 & 0.35 \\
Number of male-initiated copulation attempts and copulations & $6.34 \pm 0.81$ & $9.72 \pm 0.92$ & 2.46 & $\mathbf{0 . 0 1 4}$ \\
Overall number of copulation attempts and copulations & $6.86 \pm 0.83$ & $9.90 \pm 0.90$ & 2.19 & $\mathbf{0 . 0 2 9}$ \\
Number of successful copulations & $1.93 \pm 0.43$ & $2.59 \pm 0.35$ & 2.97 & $\mathbf{0 . 0 4 9}$ \\
Number of copulation attempts and copulations with female resistance & $4.69 \pm 0.72$ & $8.38 \pm 0.95$ & 2.92 & $\mathbf{0 . 0 0 4}$ \\
Probability of resistance to male-initiated copulation attempts and copulations & $0.76 \pm 0.06$ & $0.82 \pm 0.05$ & 0.68 & 0.50 \\
Number of copulation attempts and copulations with distress calls & $0.93 \pm 0.25$ & $4.10 \pm 0.84$ & 3.59 & $<\mathbf{0 . 0 0 1}$ \\
Proportion distress calls in male-initiated copulation attempts and copulations & $0.22 \pm 0.06$ & $0.39 \pm 0.06$ & 2.30 & $\mathbf{0 . 0 2 2}$
\end{tabular}

4 Values for 'Absence' (of dominant male) and 'Presence' (of dominant male) are given as mean \pm SE. $N_{\text {females }}=29, N_{\text {males }}=53$. Significant $P$ 5 values are presented in bold. 
8 Table 2. Female mating behaviour in the absence and presence of an additional, dominant male

\begin{tabular}{lllll}
\hline Variable & $d f$ & $F$ & $P^{9}$
\end{tabular}

Number of copulation attempts and copulations with resistance

$\begin{array}{lrrr}\text { Absence or presence of an additional male } & 1,53 & 1,66 & 0.20 \\ \text { Number of male-initiated copulation attempts and copulations } & 1,53 & 255.10 & <\mathbf{0 . 0 0 1}\end{array}$

Number of copulation attempts and copulations with distress calls

$\begin{array}{lccc}\text { Absence or presence of an additional male } & 1,53 & 5.62 & \mathbf{0 . 0 2 9} \\ \text { Number of male-initiated copulation attempts and copulations } & 1,53 & 19.07 & <\mathbf{0 . 0 0 1}\end{array}$

$10 \quad N_{\text {females }}=29, N_{\text {males }}=53$. Significant $P$ values are presented in bold. 